\title{
TESTING A SPATIALLY EXPLICIT, INDIVIDUAL-BASED MODEL OF RED-COCKADED WOODPECKER POPULATION DYNAMICS
}

\author{
Karin SchiegG, ${ }^{1,3}$ Jeffrey R. Walters, ${ }^{1}$ And Jeffery A. Priddy ${ }^{2}$ \\ ${ }^{1}$ Department of Biology, Virginia Polytechnic Institute and State University, Blacksburg, Virginia 24061-0406 USA \\ ${ }^{2}$ Duke University, Nicholas School of the Environment, Marine Laboratory, 135 Marine Laboratory Road, Beaufort, \\ North Carolina 28516-9712 USA
}

\begin{abstract}
Stochastic population models are widely used to assess extinction risk under various management scenarios, but due to the lack of independent data, such models are tested only rarely. Here we evaluate the predictive accuracy of a stochastic, spatially explicit, individual-based model of the population dynamics of the Red-cockaded Woodpecker by comparing simulated data with independent empirical data sets from two populations. We examined primary model predictions such as population size and number of territories, and secondary predictions such as population structure, dispersal success, natal dispersal distances, and age distributions. The model predicted most evaluated parameters with high accuracy, but model performance could be enhanced by including pioneering behavior and by improving estimates of male and female dispersal behavior. We judge our model to provide reliable predictions when applied to real populations, with a few specific exceptions.

Key words: extinction risk; management scenarios; Picoides borealis; pioneering; population modeling; PVA, Red-cockaded Woodpecker; spatially explicit individual-based model; stochasticity; territory budding; validation.
\end{abstract}

\section{INTRODUCTION}

Spatially explicit, individual-based models (SIBMs) constitute one of the most complex types of population models. They are attractive because of the level of mechanistic detail that can be incorporated into them, and have rapidly proliferated in various fields in ecology. However, their credibility and value are still debated (Bart 1995, Grimm 1999, Wiegand et al. 2004). SIBMs attempt to link landscape-scale processes with individual behavior, but these relationships usually are poorly understood (Lima and Zollner 1996). In addition, SIBMs typically require extensive data for parameterization, making compounding of model error a likely possibility (Conroy et al. 1995). Specifically, these models often include movement parameters such as dispersal rates and directions, in addition to the mortality and fecundity parameters characteristic of simpler models. Estimation of the former parameters is notoriously difficult, and is seldom based on extensive, unbiased samples. The need for accurate estimates of variance in order to incorporate demographic and environmental stochasticity into SIBMs potentially is another source of substantial model error (Taylor 1995, McCarthy et al. 2000).

Although the complexity of SIBMs makes achieving precision and accuracy a daunting task, at the same

Manuscript received 22 September 2004; revised 14 December 2004; accepted 26 January 2005. Corresponding Editor: T. R. Simons.

${ }^{3}$ Present address: Institute of Zoology, University of $\mathrm{Zu}-$ rich, Winterthurerstr. 190, CH-8057, Zurich, Switzerland E-mail: kschiegg@zool.unizh.ch time it results in a powerful tool for exploring and learning about the dynamics of a system. Credibility and accuracy of any model should be enhanced by thorough validation, the comparison of a model's predictions with empirical data. Cycles of model validation and model revision based on validation results can greatly improve the understanding of a system. Validation, however, requires data not used for model building, which are rarely available, and no standards for testing population models against real data have been established (Rykiel 1996, McCarthy and Broome 2000), although a variety of metrics are available (Dent and Blackie 1979, Reynolds et al. 1981, Mayer and Butler 1993, Power 1993, Loehle 1997). Brook et al. (2002) showed that five of the most commonly applied packages for population viability analyses (PVA) produced concordant and unbiased predictions. However, this study compares predicted with empirically observed extinction rates, which provides little information about model precision because projected extinction rate depends on the average extinction risk of all the species in the data sets (Ellner et al. 2002). Further, models designed for a specific species or system, as are most SIBMs, are tested only rarely.

Population models generate both primary and secondary predictions (Bart 1995). Primary predictions such as population trend or extinction probability generally are the outputs of greatest interest to managers. Evaluation of these predictions indicates the model's capability to accurately forecast population size and distribution, i.e., its predictive validity. Secondary model predictions indicate structural validity. In the 
case of SIBMs, they typically involve individual-level processes, e.g., dispersal distance and probability of transition from nonbreeding to breeding status. Secondary predictions usually are not used for management decisions, but they reveal the underlying processes of population dynamics. They are more directly linked to input parameters and, hence, they facilitate identifying sources of error. A model can be accepted as predictively valid but may fail tests for structural validity if errors compensate each other, leading to congruence of predicted and observed data (Rykiel 1996).

Previously, we constructed a SIBM depicting the population dynamics of Red-cockaded Woodpeckers (Picoides borealis) based on an extensive demographic data set (Letcher et al. 1998). The model has been used for population viability analyses (Letcher et al. 1998, Walters et al. 2002), for evaluating accumulation of inbreeding in small populations (Daniels et al. 2000), and for exploring dispersal success in fragmented landscapes (Schiegg et al. 2002). However, the model has not been validated previously, but it has been shown to have low sensitivity for any of the main input parameters (Letcher et al. 1998). In this paper, we apply the model to two real populations and compare simulated and observed population dynamics. One of the populations examined was the source of the data used to construct the model. Analysis of this population thus might be termed model verification, although we only used data that had been collected after the model had been built. Analysis of the second population can be termed model validation, because no data from it were used for model building. Our objectives were to (1) assess the accuracy of the model; (2) find its weakest parts; and (3) determine how the model, and thus the understanding of population dynamics, could be improved.

\section{Methods \\ Model description}

The model was designed to perform population viability analyses of Red-cockaded Woodpecker populations including the simulation of demographic and environmental stochasticity. Specifically, we focused in previous applications on the effects of population size and the spatial arrangement of the territories on viability and social structure of the model populations (Letcher et al. 1998, Schiegg et al. 2002, Walters et al. 2002). The Red-cockaded Woodpecker is an endangered, cooperatively breeding species that lives on permanent territories in groups consisting of a monogamous breeding pair and $0-4$ adult helpers.

The model is based on extensive demographic data collected from 1982 to 1994 from the North Carolina Sandhills population, one of the largest remaining Redcockaded Woodpecker populations, containing $\sim 580$ groups and located in south-central North Carolina (Carter et al. 1983, Walters et al. 1988). Values of mod- el parameters and equations used are listed in the Appendix.

The model can be run with hypothetical or real landscape maps, containing territories at fixed locations and nonbreeding space that the birds must cross to find territories. A territory is removed from the landscape when it is abandoned for more than five consecutive years. New territories are formed solely by budding, i.e., the splitting of an existing territory into two, which occurs with an annual probability of $1 \%$. Budding is commonly found in cooperative breeders and is the most frequent means by which new territories are added to real Red-cockaded Woodpecker populations (Hooper 1983, Doerr et al. 1989). Typically, it is a helper male within the resident group that performs budding, as a means to acquire breeding status. Pioneering, i.e., the occupation of vacant habitat by construction of a new cavity tree cluster, may occur as well (Hooper et al. 1991), but is observed only rarely (Conner et al. 2001). Territories are circular, with a radius varying between 0.3 and $0.5 \mathrm{~km}$, depending on population density. The model permits budding only if sufficient space can be created by compression of the original territory and neighboring territories to contain a new territory of minimum diameter. Territory size is not otherwise linked to probability of budding, nor is it linked to bird fecundity or mortality.

Males and females behave according to their status class. Birds were classified as fledglings, dispersers (i.e., individuals without territory affiliation), or breeders. Males additionally could be classified as solitary males (unmated male holding a territory) or as helpers. Male fledglings either stay as helpers on their natal territory or disperse. Dispersing males compete for breeding vacancies within their search range $(3 \mathrm{~km})$ to become breeders, or for empty territories to become a solitary male. Helpers attain breeding status by inheriting their natal territory or by competing successfully for a breeding vacancy in their vicinity (i.e., within 3 $\mathrm{km})$. They become solitary males on their natal site when both breeders die or when the male breeder dies and the helper's mother leaves the territory to avoid mating with her son. Solitary males become breeders when a dispersing female finds them.

All surviving female fledglings become dispersers, i.e., all disperse from their natal territory in their first year. Subsequently, they either become breeders by competing successfully for a breeding vacancy (i.e., a territory containing a solitary male) within their search range $(3 \mathrm{~km})$, or they become floaters (i.e., they remain in the disperser class). Females leave their breeding territory when their son or father replaces their mate.

Dispersal occurs in random directions and in a straight line. Search behavior is incorporated in the dispersal process by allowing birds to compete for all breeding vacancies within $3 \mathrm{~km}$ of their dispersal path. Dispersal speed depends on the individual's sex and status class. When birds cross the boundary of the land- 
scape, they are excluded from further simulation. Mortality rates are specific to sex and status class, and reproductive output depends on the probability of nesting successfully and the probable number of fledglings produced. Both depend, in turn, on the breeders' age and the number of helpers on the territory (see Appendix). Competition for vacancies takes place at each time step (three months). For male vacancies, the oldest resident helper wins the competition. If no resident helpers are present, and for all female vacancies, nonbreeders from nearby territories and dispersing birds within range compete for the vacancy. When several males compete for the vacancy, the closest bird wins; if there is a tie, the oldest bird wins. Among females, the older bird always wins over the younger bird.

Demographic stochasticity is incorporated into the simulations by applying to each individual annual survival probabilities, annual status transition probabilities of male fledglings, and probabilities of producing different numbers of fledglings. This is accomplished by drawing a deviate from a random uniform distribution and determining whether or not the deviate is less than the appropriate probability value. Environmental stochasticity is incorporated by varying survival probabilities and probabilities of producing different numbers of fledglings each year. This is accomplished by determining the variance among years in these parameters across the 14 years of data from the North Carolina Sandhills population, and then drawing randomly each year from the resulting empirical distribution to determine that year's probability values.

\section{Validation runs}

We used data from Camp Lejeune Marine Base, North Carolina, USA (CL), and from the North Carolina Sandhills $(\mathrm{SH})$ to validate the model. The simulation runs were performed with landscape maps from these locations. Territory centers were the UTM coordinates of the nest tree (CL) or the arithmetic mean of the UTM coordinates of all foraging locations obtained from a group during regular breeding season monitoring (SH) (Walters et al. 1988). Our data sets cover the whole CL population, but in SH, only 253 out of $581(43.5 \%)$ known territories were monitored. Because we knew the locations of the unmonitored territories in $\mathrm{SH}$, we included them in our landscape map. For the validation procedures, however, we only used the data from monitored territories. The number and location of territories varies slightly between years. We based our landscape maps on the earliest year of monitoring in which we had reliable information of the location of each territory, as well as population structure. This was 1988 in CL and 1987 in SH. In the case of the SH population, the years 1987-1994 overlap with the years used for model building. Because validation requires data not used for model parameterization, we based comparisons between model output and real data on the subsequent years, i.e., 1995-1999. We chose to run the model based on a map of 1987 and to discard the output from the first eight years of simulation because we expected potential model errors to accumulate over time. Thus, running the simulations based on conditions in 1987 provides a stronger test than if we had used a 1995 map.

We used the same initial conditions of population structure as in previous simulations (Letcher et al. 1998, Daniels et al. 2000, Schiegg et al. 2002, Walters et al. 2002) i.e., $100 \%$ territory occupancy with $90 \%$ breeding pairs and $10 \%$ solitary males, and a number of helpers equal to half of the number of territories. No dispersing birds or fledglings were present initially. We specified an annual immigration rate equal to the rate observed in CL (1.6 females/year) and assumed no immigration into $\mathrm{SH}$. We produced and analyzed 100 replicated runs for both study populations. In previous analyses, we found that the model converged at $\sim 70$ runs. Further, predictions of CL population size after 12 years of simulation based on 100 runs were only $0.8 \%$ different from predictions based on 500 runs. We therefore consider 100 runs per simulation sufficient to obtain consistent results, and we employed this sample size in all analyses.

\section{Validation procedure}

Population models can be tested by two main approaches, (1) qualitatively comparing model predictions with observational data, and (2) quantitative comparisons based on statistical testing (McCarthy et al. 2001). Because all parameters examined here form either time series or frequency distributions, thereby making data points interdependent, we used a qualitative assessment of model performance. We calculated means and standard deviations of each validated parameter over all replicated runs and then (visually) compared the obtained values to the empirical data. We validated the following primary model predictions: population size (number of breeding pairs), number of territories gained or lost, and social structure (numbers in each status class).

Comparing average population projections with historical data reflects how well a model captures the dynamics of a system (Beissinger and Westphal 1998), but does not verify how accurately stochasticity is modeled (McCarthy et al. 2001). One remedy for this problem is to test secondary predictions, which are the result of multidimensional processes during a simulation (Beissinger and Westphal 1998). We examined the following secondary model predictions: natal dispersal distances (distance from natal site to site of first reproduction), the percentage of male and female fledglings obtaining breeding status at age 1 and at anytime in their life, age distribution at time of first obtaining breeding status, and age distribution of male and female breeders at the end of the simulation period. To calculate the number of birds obtaining a breeding position at any time in their life, we did not consider birds 


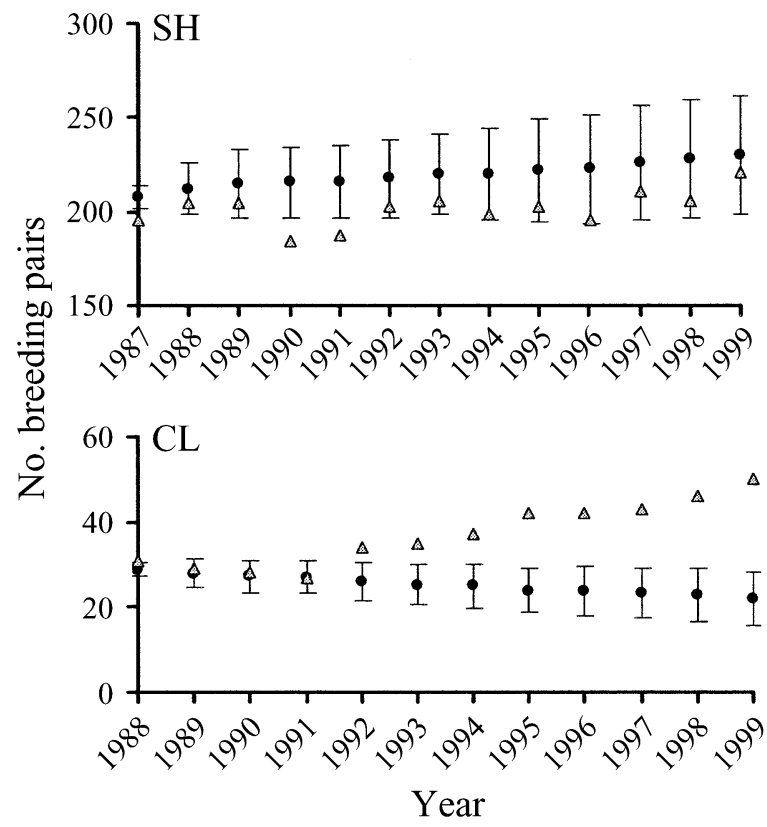

FIG. 1. Number of breeding pairs over time in the Redcockaded Woodpecker populations of the Sandhills (SH) and Camp Lejeune (CL) study areas. Given are values of the real (triangles) and simulated (means $\pm \mathrm{SD}, n=100$ runs, circles) populations.

that were born in the last four years of simulation and observation time. Some individuals, especially helpers, may not become breeders until age four, or even later in a few cases. The SH data cover only five years (1995-1999) and therefore were not included in this analysis.

The model classifies each male fledgling as either helper or disperser, according to empirically observed proportions. Consequently, a male that becomes a breeder on a neighboring territory in his first year can belong either to the disperser or helper class. In the real data sets, all males that obtained breeding status on a territory other than their natal territory in their first year were classified as dispersers.

\section{RESUlts \\ Population size}

The CL population grew from 31 breeding pairs in 1988 to 50 breeding pairs in 1999 . The model population showed a slight decline from an initial $28.9 \pm$ 1.7 breeding pairs (mean $\pm \mathrm{SD}, n=100$ simulation runs) to $22.0 \pm 6.3$ breeding pairs after 12 years of simulation (Fig. 1). Hence, population size as predicted by the model was only $44 \%$ of the size actually observed.

In the SH study area, the real population increased from 203 breeding pairs in 1995 to 221 pairs in 1999. The model populations consisted, on average, of 221.7 \pm 27.5 breeding pairs $(n=100)$ in the ninth year of simulation, which corresponds to 1995 , when valida- tion started (see above), and grew to $230.3 \pm 31.4$ pairs after 13 years of simulation (in 1999). In this population, predicted population size differed from the empirical size by only $4 \%$.

\section{Number of territories}

The real CL population gained 13 territories, seven by pioneering and six by budding; no territory was lost during the study period. In contrast, the simulated populations gained only $3.7 \pm 1.7$ territories $(n=100)$ during the 12 years of simulation, but lost $4.1 \pm 3.4$ territories during the same period of time.

The SH population gained nine territories between 1995 and 1999 (eight by budding, one by pioneering), and no territory was abandoned during that time. The simulated populations gained on average $9.5 \pm 3.5$ territories $(n=100)$, but lost $6.5 \pm 7.8$ territories during the five years of simulation used for the analyses.

\section{Social structure}

The social structure of the real and the simulated populations at the end of observation and simulation time, respectively, agreed well in both study areas (Fig. 2). Model populations contained slightly fewer helpers and more solitary males than the real populations.

\section{Dispersal distances}

In the CL population, median dispersal distances in both sexes in the simulations were smaller than the empirical values. Median natal dispersal distances of males in the simulated SH population were in good accordance with the real data, but for females, values from the simulations were smaller than empirically measured distances (Fig. 3, Table 1).

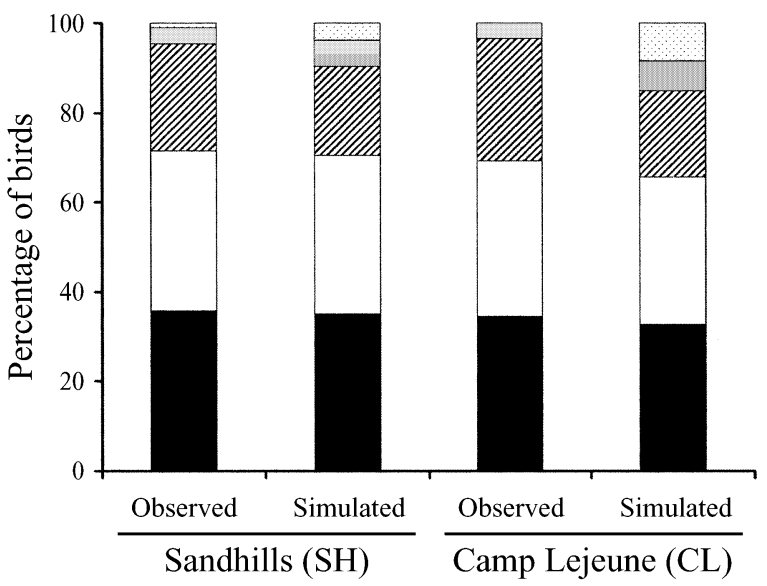

FIG. 2. Social structure of the real and simulated (means over 100 runs) populations at the end of observation and simulation time, respectively, i.e., after 12 (CL) and 13 (SH) years. Histogram fills are: black, female breeders; white, male breeders; hatched, helpers; gray, floaters; dotted, solitary males. 


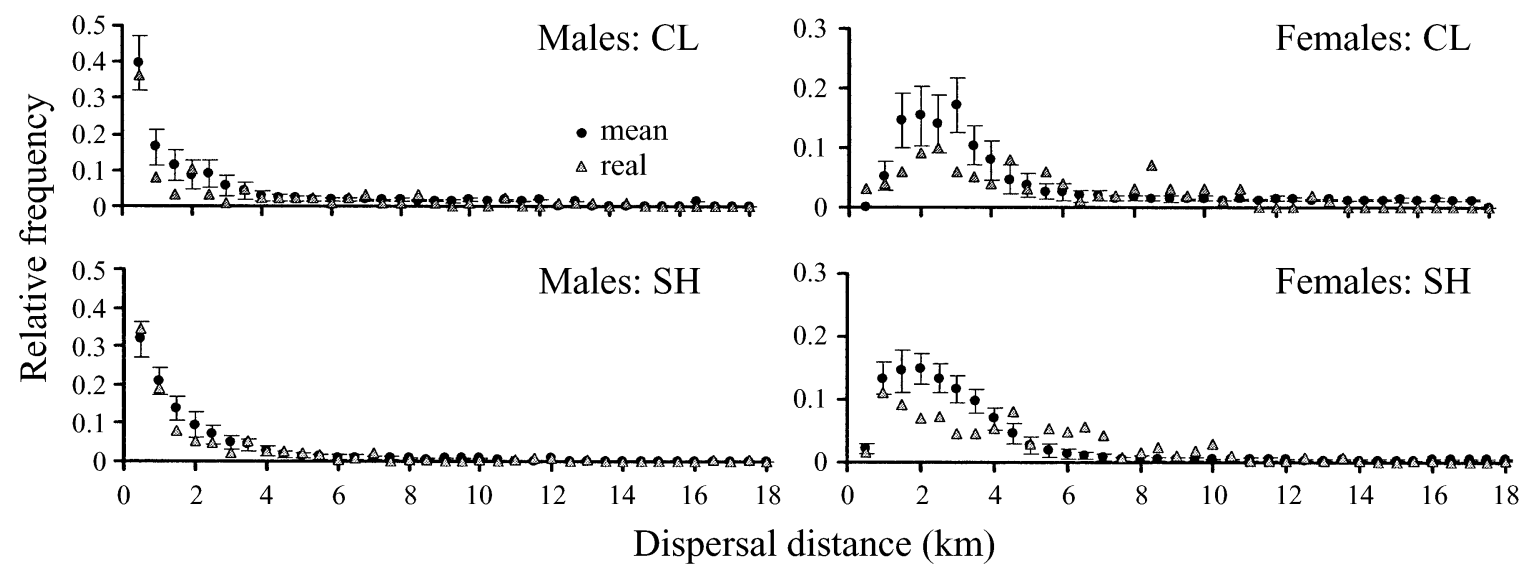

FIG. 3. Distribution of natal dispersal distances of male and female Red-cockaded Woodpeckers. Depicted are values for the real Sandhills $(\mathrm{SH})$ and Camp Lejeune $(\mathrm{CL})$ populations, as well as means $( \pm \mathrm{SD})$ of the simulated populations $(n=100$ runs). Not included are two long-distance dispersers $(>25 \mathrm{~km})$ in the real $\mathrm{SH}$ population.

\section{Dispersal success}

In $\mathrm{CL}$ and $\mathrm{SH}$, empirical and model data on male dispersal success, as measured by the percentage of fledglings that obtained breeding status at age 1 year, were congruent, but the model overestimated female dispersal success (Table 2). In both populations, the simulated success of males was lower than that of females, as it is in real populations. Fewer fledglings appeared in the simulation of the CL population than in the real data, because model population sizes were smaller than the actual size (see above). In the $\mathrm{SH}$ population, model population sizes were larger than the real size, resulting in more fledglings in the simulated than in the empirical data.

A second measure of dispersal success is the percentage of fledglings that obtained a breeding position at any time in their life. The model only slightly underestimated success in both sexes (Table 3 ).

\section{Age at first breeding}

The model simulated well the overall age distribution of male and female first-time breeders (Fig. 4). The greatest discrepancies occurred in the frequency of oneyear-old female breeders. The model predicted $94 \%$ (both in $\mathrm{CL}$ and $\mathrm{SH}$ ) of female first-time breeders to be one-year-olds, whereas the empirical values were lower (63\% in CL and $89 \%$ in $\mathrm{SH}$ ).

\section{Age distribution of all breeders}

The age distribution of male and female breeders after 12 (CL) and $13(\mathrm{SH})$ years of simulation agreed with the corresponding age distributions in 1999 in the real populations (Fig. 5). In CL, however, the frequency of one-year-old breeders of both sexes was predicted to be higher than that observed in the empirical data.

\section{DisCUSSION}

\section{Accuracy of model predictions}

The most striking difference between model and real data was the discrepancy between predicted and observed population size in CL. The model failed to simulate the population growth that has occurred in the real population. The major precondition for natural population growth in Red-cockaded Woodpeckers is the creation of new territories, either by budding or pioneering (Walters 1991). In the simulations, territories are added only by budding, and the chance of each territory to be split into two is $1 \%$ per year. This means that when modeling the CL population, initially containing 28 territories, about one territory is added every four years. Although the observed rate of budding in the CL population during the study period $(0.6 \%$ per year; Conner et al. 2001) was similar to the simulated rate, the pioneering rate in the CL population was unusually high, accounting for a population growth rate

TABLE 1. Natal dispersal distances ( $\mathrm{km}$, medians and interquartile ranges) of Red-cockaded Woodpeckers in simulated (medians over 100 runs) and real populations.

\begin{tabular}{lcccc}
\hline \hline Sex & CL-simulated & CL-real & SH-simulated & SH-real \\
\hline Males & $0.8(0.0-1.9)$ & $1.6(0.0-4.9, n=85)$ & $0.9(0.0-2.0)$ & $0.9(0.0-3.1, n=186)$ \\
Females & $2.0(1.2-2.9)$ & $4.2(2.2-7.7, n=99)$ & $2.2(1.4-3.2)$ & $3.9(1.7-6.2, n=260)$ \\
\hline
\end{tabular}

Notes: CL, Camp Lejeune study area; SH, Sandhills study area; $n$ is the number of dispersal events in the real populations. 
TABLE 2. Number of birds that obtained a breeding position at age 1 in relation to the total number of fledglings and dispersal strategy, from simulated (mean $\pm \mathrm{SD}, n=100$ simulated runs) and real populations.

\begin{tabular}{ccccc}
\hline \hline Sex and age & CL-simulated & CL-real & SH-simulated & SH-real \\
\hline Male fledglings (total) & $229.0 \pm 35.7$ & 281 & $890.3 \pm 129.6$ & 618 \\
Breeding status age $1_{\text {Disp }}$ & $12.2 \pm 4.1$ & 13 & $42.6 \pm 8.4$ & 34 \\
& $(5.5 \pm 1.9 \%)$ & $(4.6 \%)$ & $(6.2 \pm 0.02 \%)$ & $(5.5 \%)$ \\
Breeding status age $1_{\text {Hlp }}$ & $8.3 \pm 3.8$ & 8 & $27.5 \pm 7.1$ & 7 \\
& $(3.7 \pm 1.7 \%)$ & $(2.8 \%)$ & $(3.9 \pm 0.01 \%)$ & $(1.1 \%)$ \\
Female fledglings (total) & $228.1 \pm 37.8$ & 291 & $707.4 \pm 103.5$ & 713 \\
Breeding status age 1 & $71.3 \pm 10.7$ & 58 & $226.3 \pm 127.0$ & 184 \\
& $(31.1 \pm 3.9 \%)$ & $(19.9 \%)$ & $(32.3 \pm 3.5 \%)$ & $(25.8 \%)$ \\
\hline
\end{tabular}

Notes: CL, Camp Lejeune study area; SH, Sandhills study area. Subscript abbreviations for age 1 males are: Disp, dispersing males; Hlp, helpers.

of $1.5 \%$ per year, as opposed, e.g., to $0.06 \%$ and $0.3 \%$ in the $\mathrm{SH}$ and Croatan National Forest populations, respectively, two other populations our research group monitored during this same period (Conner et al. 2001). Furthermore, CL has implemented an increasingly intensive management program specifically designed to stimulate population growth. New territories were created by constructing artificial cavities, and abandonment of existing territories was lowered by reducing hardwood midstory vegetation and replacing lost cavities with artificial cavities. Discrepancies between simulated and actual population growth likely to some extent reflect the success of this program. Five new groups were added to the population by occupation of new territories with artificial cavities. This represents a direct effect of management on population size, and there may have been an additional indirect effect on the real population over the period of the simulation due to the effect of increased population density on population dynamics. This effect could be manifested not only in increased population growth through budding, but also in reduced territory abandonment. Territories in virtual landscapes were designated abandoned when unoccupied for five consecutive years, and local population density has a large influence on whether a vacant territory is detected by a dispersing bird (Schiegg et al. 2002).

Management actions to reduce territory abandonment cannot account for discrepancies between real and simulation population behavior, because they were de- signed to maintain territory quality. Thus abandonment should have been due to population dynamics alone rather than to habitat degradation, which is what the model assumes. Another factor that may have contributed to the discrepancy in the number of abandoned territories between model and real populations is that unpaired males tended to be overrepresented in the former. Almost all abandoned territories were previously occupied by unpaired males.

The absence of pioneering represents a deficiency in the model in applications to populations in which pioneering occurs at greater than negligible rates. Besides CL, only one other population (Francis Marion National Forest; Hooper et al. 1991) is reported to have this characteristic. Unfortunately, the conditions that favor pioneering are still poorly understood, and there is no basis in empirical data to add such behavior to the model. Should the model be applied to a population in which pioneering often occurs, such as CL, the budding rate could be adjusted to account for additions of new territories. This, however, does not exactly mimic pioneering behavior because budding decreases distances between neighboring territories, whereas pioneering does not. The spatial distribution of territories has been shown to greatly influence dispersal success and, ultimately, population dynamics in this species (Schiegg et al. 2002).

The model tended to overestimate female dispersal success, resulting in predicted dispersal distances that were shorter than observed ones. Too many females

TABLE 3. Number of birds that obtained a breeding position at any time in their life in relation to the total number of fledglings and dispersal strategy, from simulated (mean $\pm \mathrm{SD}, n=$ 100 simulation runs) and real populations.

\begin{tabular}{lrc}
\hline \hline \multicolumn{1}{c}{ Sex and age } & CL-simulated & CL-real \\
\hline Male fledglings (total) & $154.2 \pm 20.4$ & 185 \\
Breeding status any age $_{\text {Disp }}$ & $13.4 \pm 3.8(8.8 \pm 2.7 \%)$ & $23(12.4 \%)$ \\
Breeding status any age $_{\mathrm{Hlp}}$ & $31.5 \pm 6.4(20.4 \pm 3.1 \%)$ & $43(23.2 \%)$ \\
Female fledglings (total) & $152.5 \pm 22.5$ & 190 \\
Breeding status any age & $55.4 \pm 7.4(33.2 \pm 3.8 \%)$ & $69(36.3 \%)$ \\
\hline
\end{tabular}

Notes: CL, Camp Lejeune study area; SH, Sandhills study area. Subscript abbreviations for males are: Disp, dispersing males; Hlp, helpers. Fledglings born in the last four years of simulation and observation are not included because their dispersal success cannot be determined. 

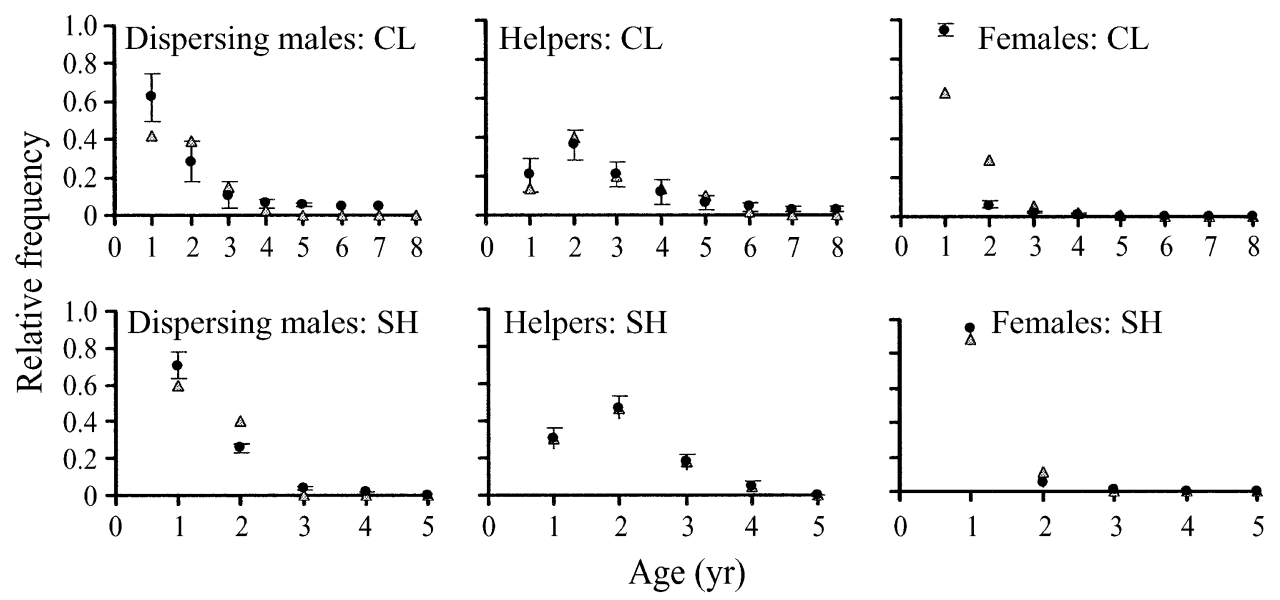

FIG. 4. Age of male and female Red-cockaded Woodpeckers at the time of first obtaining breeding status. Depicted are values for the real Sandhills (SH) and Camp Lejeune (CL) populations (triangles), as well as means ( \pm SD) of the simulated populations ( $n=100$ runs, circles).

became breeders at age 1 and, consequently, too many one-year-old birds occurred in the breeding population when compared to the empirical data. These effects were more pronounced in the CL population. In this population, the model underestimated dispersal distances and overestimated the proportion of one-yearold breeders for males as well. We conclude that our estimate of search ranges in both sexes is too large, resulting in elevated dispersal success. Because the model is more sensitive to changes in female than male search range in small populations (Letcher et al. 1998), the impact of a small error in this parameter is likely to be greater for females than for males. Geographic variation in demography is another possible source of model error. Birds in coastal populations like CL exhibit higher survival and lower fecundity than birds in inland populations like SH (Conner et al. 2001). This may result in better model performance for some populations than others, a possibility that could be assessed by using parameter estimates derived from the CL population. However, small errors in fecundity and survival parameters cannot account for the discrepancy in real and model population size for CL, or for discrepancies in dispersal success. Because of confounding factors such as management activity at CL, it will still be difficult to determine how much the use of location-specific parameters improves model performance. It might be more productive to apply the model to a number of additional populations to decide whether site-specific information improves the accuracy of the projections.

On the other hand, the model provided accurate predictions of other variables more closely tied to survival and fecundity, such as population structure at the end of simulation time, and distributions of natal dispersal

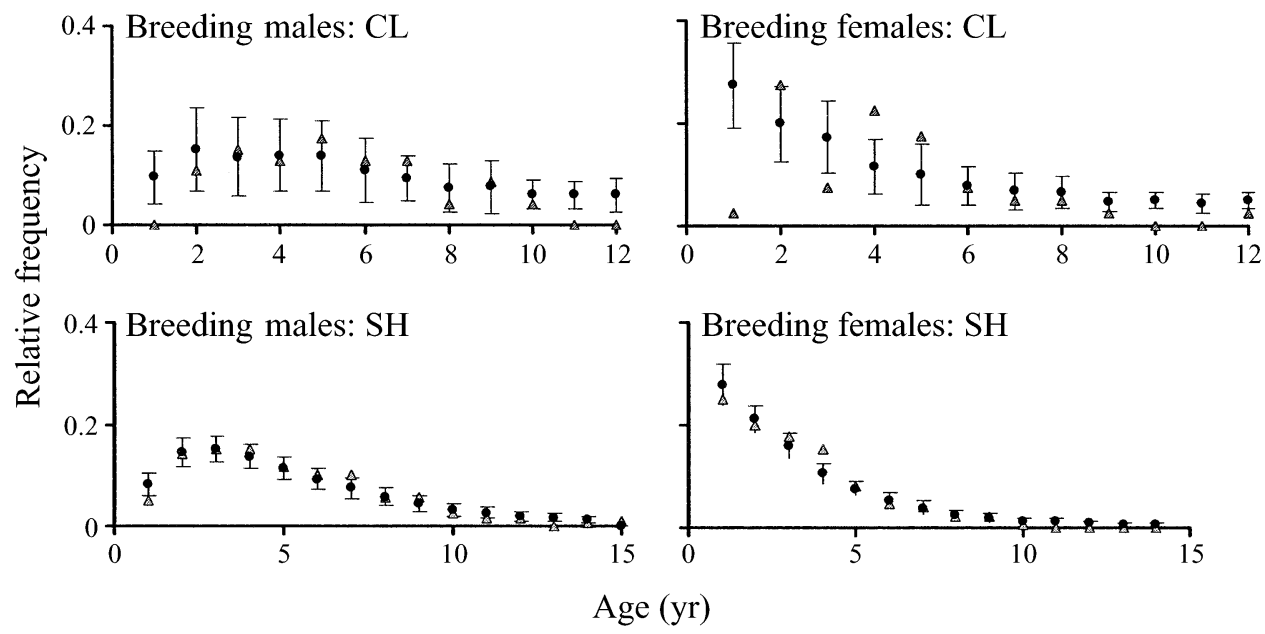

FIG. 5. Age distribution of breeding male and female Red-cockaded Woodpeckers in 1999 (real populations, triangles) and after 13 years (Sandhills, SH) and 12 years (Camp Lejeune, CL) of simulation (simulated data, means \pm SD, $n=100$ runs, circles). 
distances and ages of the breeding population. The values of these variables are influenced by various parameters during the simulation process, e.g., dispersal speed and direction, as well as mortality and fecundity. The precise prediction of these output variables therefore increases confidence in general model performance and in the conclusions drawn in previous and future applications of the model.

\section{Structural assumptions of the model}

Model performance is influenced not only by parameters that can be validated, but also by some general decisions in the early stage of model building. In the following, we discuss the most important assumptions that we made with respect to their impact on modeling results.

Variation in habitat quality among territories has not been incorporated into the model yet, because quantitative relationships between habitat quality and demography only recently have been established in this species. Reproductive success is related to habitat structure, being highest in territories with open pine stands with large, old tree trees and a rich, diverse ground cover (James et al. 1997). Incorporating habitat quality in the model might be appropriate for landscapes with high temporal or spatial variation of habitat quality, but it is not clear that adding spatial variation to stochastic variation in reproduction will have much impact on output parameters. There may be a larger impact in cases in which overall habitat quality in a population, and hence mean reproduction, is extremely low or extremely high. This may be a factor in discrepancies between real and model data for CL, if habitat quality at CL is unusually good.

Territory size is modeled solely as a function of population density, unrelated to reproductive success. In real Red-cockaded Woodpecker populations, home range size is additionally influenced by habitat quality (Engstrom and Sanders 1997). This may lead to an underestimate of population density in high-quality habitats. The presence of helpers (Lennartz et al. 1987, Beyer et al. 1996) and the age of the breeders (Lennartz et al. 1987, Walters 1990) are clearly the prime determinants of productivity in Red-cockaded Woodpeckers, however, and we do not expect significant error to arise from an interaction among territory size, habitat quality, and population density.

Simulating dispersal is one of the most crucial tasks in population modeling (South 1999). We assumed that the birds dispersed in random directions and in a straight line, with constant speed and search range throughout the year. Additionally, our landscapes have nonreflecting boundaries, so birds that move beyond territories are lost to the population. These dispersal rules, as opposed to dispersal directed toward the nearest vacancy, for instance, may make territory location inefficient. Still, the model tended to overestimate, rather than underestimate, dispersal success, so there is no need to alter our basic dispersal rules other than search range.

Inbreeding has been demonstrated to reduce fitness in Red-cockaded Woodpeckers (Daniels and Walters 2000, Schiegg et al. 2002), but it is not integrated in the model version that was validated here. Inbreeding depression reduces long-term survival of small populations; hence we did not expect substantial bias in the model predictions for the populations that we examined.

\section{Conclusions}

Here we have demonstrated that population dynamics as complex as those of cooperative breeders can be modeled with high precision. The model performed well in tests of validity for the population from which the data used in model building were obtained. That predictions were less accurate for the CL population may be due to effects of management and the absence of pioneering from the model. Further, the model performed well in tests of structural validity in both populations. The only deficiency identified was in the search range parameter. Research on dispersal behavior focusing specifically on movements of individuals between summer and early spring would be useful. SIBMs have been viewed with skepticism because they are highly complex. However, this feature also allows for in-depth testing of several model dimensions and thereby facilitates error identification, as shown by our study, which is, in its detail, perhaps unique. Given the outcome of the validation process presented here and the many dimensions included, we are confident that predictions made by our model are credible, especially when the model is used to make relative, rather than absolute, predictions. Further applications of the model may include identification of territories critical for population viability, or the assessment of the number and spatial location of newly treated territories necessary to sustain existing populations.

\section{ACKNOWLEDGMENTS}

We thank Michael McCarthy for constructive comments on earlier drafts of the manuscript, and we also acknowledge Benjamin Letcher and Larry Crowder for their work on the model, and Jay Carter and Phillip Doerr, whose continuing efforts contribute greatly to the extension of our data set. We are grateful to the many graduate students, field technicians, and undergraduate students who contributed to the collection of the data used in this study, and to the Department of Defense, U.S. Army, Fort Bragg and Marine Corps Base Camp Lejeune, and the National Science Foundation (BSR-8307090 and BSR-8717683) for supporting data collection. This paper was supported by the Swiss National Science Foundation (Grant 81EZ-57341 to K. Schiegg).

\section{Literature Cited}

Bart, J. 1995. Acceptance criteria for using individual-based models to make management decisions. Ecological Applications 5:411-420.

Beissinger, S. T., and M. I. Westphal. 1998. On the use of demographic models of population viability in endangered 
species management. Journal of Wildlife Management 62 821-841.

Beyer, D. E., Jr., R. Costa, R. G. Hooper, and C. A. Hess 1996. Habitat quality and reproduction of red-cockaded woodpecker groups in Florida. Journal of Wildlife Management 60:826-835.

Brook, B. W., D. W. Tonkyn, J. J. Q'Grady, and R. Frankham. 2002. Contribution of inbreeding to extinction risk in threatened species. Conservation Ecology 6(1):16. 〈http:// www.consecol.org/vol6/iss 1/art16/>

Carter, J. H.,III, R. T. Stamps, and P. D. Doerr. 1983. Status of the red-cockaded woodpecker in the North Carolina sandhills. Pages 24-29 in D. A. Wood, editor. Red-cockaded Woodpecker Symposium II. Florida Game and Freshwater Fisheries Commission, U.S. Fish and Wildlife Service, Atlanta, Georgia, USA.

Conner, R. N., D. C. Rudolph, and J. R. Walters. 2001. The red-cockaded woodpecker: surviving in a fire-maintained ecosystem. University of Texas Press, Austin, Texas, USA

Conroy, M. J., Y. Cohen, F. C. James, Y. G. Matsinos, and B. A. Maurer. 1995. Parameter estimation, reliability, and model improvement for spatially explicit models of anima populations. Ecological Applications 5:17-19.

Daniels, S. J., J. A. Priddy, and J. R. Walters. 2000. Inbreeding in small populations of red-cockaded woodpeckers: in sights from a spatially-explicit individual-based model. Pages 129-147 in A. G. Young and G. M. Clarke, editors Genetics, demography and viability of fragmented populations. Cambridge University Press, London, UK.

Daniels, S. J., and J. R. Walters. 2000. Inbreeding depression and its effects on natal dispersal in Red-cockaded Woodpeckers. Condor 102:482-491.

Dent, J. B., and M. J. Blackie. 1979. Systems simulation in agriculture. Applied Sciences Publishers, London, UK.

Doerr, P. D., J. R. Walters, and J. H. Carter III. 1989. Reoccupation of abandoned clusters of cavity trees (colonies) by red-cockaded woodpeckers. Proceedings of the Annual Conference of the Southeastern Association of Fish and Wildlife Agencies 43:326-336.

Ellner, S. P., J. Fieberg, D. Ludwig, and C. Wilcox. 2002. Precision of population viability analysis. Conservation Biology 16:258-261.

Engstrom, R. T., and F. J. Sanders. 1997. Red-cockaded Woodpecker foraging ecology in an old-growth longleaf pine forest. Wilson Bulletin 109:203-217.

Grimm, V. 1999. Ten years of individual-based modelling in ecology: what have we learned and what could we learn for the future? Ecological Modelling 115:129-148.

Hooper, R. G. 1983. Colony formation by red-cockaded woodpeckers: hypotheses and management implications. Pages 72-77 in D. A. Wood, editor. Red-cockaded Woodpecker Symposium II. Florida Game and Freshwater Fishery Commission, US Fish and Wildlife Service, Atlanta, Georgia, USA.

Hooper, R. G., D. L. Krusac, and D. L. Carlson. 1991. An increase in a population of red-cockaded woodpeckers. Wildlife Society Bulletin 19:277-286.

James, F. C., C. A. Hess, and D. Kufrin. 1997. Speciescentered environmental analysis: indirect effects of fire history on Red-cockaded Woodpeckers. Ecological Applications 7:118-129.
Lennartz, M. R., R. G. Hooper, and R. F. Harlow. 1987. Sociality and cooperative breeding of red-cockaded woodpeckers, Picoides borealis. Behavioral Ecology and Sociobiology 20:77-88.

Letcher, B. H., J. A. Priddy, J. R. Walters, and L. B. Crowder. 1998. An individual-based, spatially-explicit simulation model of the population dynamics of the endangered redcockaded woodpecker, Picoides borealis. Biological Conservation 86:1-14

Lima, S. L., and P. A. Zollner. 1996. Towards a behavioural ecology in ecological landscapes. Trends in Research in Ecology and Evolution 11:131-135.

Loehle, C. 1997. A hypothesis-testing framework for evaluating model performance. Ecological Modelling 97:153165.

Mayer, D. G., and D. G. Butler. 1993. Statistical validation. Ecological Modelling 68:21-32.

McCarthy, M. A., and L. S. Broome. 2000. A method for validating stochastic models of population viability: a case study of the mountain pygmy-possum (Burramys parvus). Journal of Animal Ecology 69:599-607.

McCarthy, M. A., D. B. Lindenmayer, and H. P. Possingham. 2000. Testing PVA models of Australian treecreepers (Aves: Climacteridae) in fragmented forest. Ecological Applications 10:1722-1731.

McCarthy, M. A., H. P. Possingham, J. R. Day, and A. J. Tyre. 2001. Testing the accuracy of population viability analysis. Conservation Biology 15:1030-1038.

Power, M. 1993. The predictive validation of ecological and environmental models. Ecological Modelling 68:33-50.

Reynolds, M. R., H. E. Burkhart, and R. F. Daniels. 1981. Procedures for statistical validation of stochastic simulation models. Forest Science 27:349-364.

Rykiel, E. J., Jr. 1996. Testing ecological models: the meaning of validation. Ecological Modelling 90:229-244.

Schiegg, K., J. R. Walters, and J. A. Priddy. 2002. The consequences of disrupted dispersal in fragmented red-cockaded woodpecker populations. Journal of Animal Ecology 71:710-721.

South, A. 1999. Dispersal in spatially explicit population models. Conservation Biology 13:1039-1046.

Taylor, B. L. 1995. The reliability of using population viability for risk classification of species. Conservation $\mathrm{Bi}$ ology 9:551-558.

Walters, J. R. 1990. Red-cockaded woodpeckers: a "primitive" cooperative breeder. Pages 67-101 in P. B. Stacey and W. D. Koenig, editors. Cooperative breeding in birds: long-term studies of ecology and behavior. Cambridge University Press, Cambridge, UK.

Walters, J. R. 1991. Application of ecological principles to the management of endangered species: the case of the redcockaded woodpecker. Annual Review of Ecology and Systematics 22:505-523.

Walters, J. R., L. B. Crowder, and J. A. Priddy. 2002. Population viability analysis for Red-cockaded Woodpeckers using an individual-based model. Ecological Applications 12:249-260.

Walters, J. R., P. D. Doerr, and J. H. Carter III. 1988. The cooperative breeding system of the red-cockaded woodpecker. Ethology 78:275-305.

Wiegand, T., E. Revilla, and F. Knauer. 2004. Dealing with uncertainty in spatially explicit population models. Biodiversity and Conservation 13:53-78

\section{APPENDIX}

Model equations and parameters are available in ESA's Electronic Data Archive: Ecological Archives A015-042-A1. 